\title{
Effectiveness on oral health of a long-term health education programme for mothers with young children
}

\author{
M. B. Kowash, ${ }^{1}$ A. Pinfield, ${ }^{2}$ J. Smith, ${ }^{3}$ and M. E. J. Curzon, ${ }^{4}$
}

\begin{abstract}
Aim To determine the effect of dental health education (DHE) on caries incidence in infants, through regular home visits by trained DH Educators over a period of 3 years.

Method A randomly selected cohort of 228 children born between 1st January and 30th September 1995, in a low socioeconomic/high caries suburb of Leeds (UK) were divided into the following groups: A) DHE focused on diet; B) DHE focused on oral hygiene instruction (OHI) using fluoride toothpaste; and $\mathrm{C}$ ) DHE by a combined diet and OHI message. DHE was given using an interview and counselling for at least 15 minutes at home every 3 months for the first 2 years and twice a year in the third year of the study. A fourth group D was given diet and OHI, at home, once a year only. All children and mothers were examined for caries and oral hygiene. A fifth group E (control) received no DHE and were never visited but examined at 3 years of age only. Results In the groups of children visited regularly only two developed caries and three had gingivitis (all in group A). In group E, however, $33 \%$ of children had caries and nine (16\%) had gingivitis. The differences in caries levels and caries risk factors between study and control groups were statistically significant $(P<0.001)$. Mothers of the study groups also showed an improvement in their own levels of gingivitis, debris and calculus scores by the second and third examinations $(P<0.001)$. Conclusion Regular home visits to mothers with infants, commencing at or soon after the time of the eruption of the first deciduous teeth, was shown to be effective in preventing the occurrence of nursing caries.
\end{abstract}

Uursing caries has been known to exist for many centuries. ${ }^{1}$ The 1 prevalence has been reported to vary between $1 \%$ and $80 \%$ worldwide, but in western societies it is believed to be between 3\% and $5 \% .^{2}$ Higher prevalence has occurred in children of lower social class, migrants and ethnic minority populations. 3,4

The aetiology of the condition is a combination of frequent consumption of fermentable carbohydrates as drinks, especially when a baby is sleeping, with on-demand breast- or bottle-feeding, oral colonisation by cariogenic bacteria (especially mutans streptococci), poor oral hygiene and poor parenting. ${ }^{5-7}$

In most cases the aetiology will be a combination of several of these events.

\footnotetext{
${ }^{1}$ Research Fellow, ${ }^{2}$ Regional Outreach Sister in Paediatrics, ${ }^{3}$ Dental Hygienist,

$4^{*}$ Professor and Head, Department of Paediatric Dentistry, Leeds Dental Institute, University of Leeds, Clarendon Way, Leeds LS2 9LU

${ }^{\star}$ Correspondence to: Professor M. E. J. Curzon

REFEREED PAPER

Received 17.06.99; accepted 10.11.99

(C) British Dental Journal 2000; 188: 201-205
}

Prevention of nursing caries can be achieved firstly, by the education of prospective and new parents and secondly, by the identification of 'high risk' children. ${ }^{8,9}$ Strategies have focused on the individual mother and child, by preventing transfer of cariogenic bacteria from mother to her infant, using preventive agents such as fluoride and teaching good oral hygiene practices. ${ }^{10}$ Communitybased approaches have also been attempted, but none has achieved any long-term effect. ${ }^{8,11}$ Moreover, dental health education (DHE) is rarely studied and evaluated in a randomised way. ${ }^{12}$

The solution to this continuing problem would seem to be programmes of DHE for young mothers, initiated at a time before the primary teeth erupt into the mouth. The need is for long-term prospective studies to assess various risk factors involving behavioural, socio-economic, educational and microbiological factors and to follow the effect of dental health education over a long period of time. The dental health messages should be practical, informal and culturally sensitive.

\section{Materials and methods}

Subjects

The ethical approval of the study was obtained from the ethics committee of the Leeds General Infirmary. A randomised selection was carried out, by the Office of Population Statistics (OPCS, UK Government), of all mothers with children born between 1 January and 30 September 1995, resident in low socio-economic/high caries suburbs of Leeds (UK). The mothers were approached directly by OPCS who obtained their consent. From this initial population some 228 mother/child pairs were inducted into the study and randomly assigned to the following active groups for dental examination and dental health education (DHE). Group A received DHE focused on diet and briefly on oral hygiene. Group B focused on oral hygiene instruction $(\mathrm{OHI})$ using children's fluoride toothpaste and briefly on diet. Group C received DHE equally balanced between diet and OHI. Each mother was given DHE using a structured interview and counselling for at least 15 minutes in her own home every 3 months for the first 2 years of the study and twice a year in the third year of the study. A fourth group D received DHE as diet and OHI once a year only for each of the 3 years.

The study design required a control group E that presented several problems. If this group of mothers and children were selected at the beginning of the study they would have consented to a study in which they would receive nothing. This would have had to be stated in the OPCS letter. If a mother consented and found herself and her child in this fifth group then she might also probably withdraw. At the same time if a mother consented to be assigned to Group E she would be sensitised to the fact that when her child was 3 -years-old there would be a dental examination and this would bias this fifth group in the study. These children would not then 
represent a 'normal' population who did not seek dental advice, if at all, until at least age 3 years or older.

The solution, as agreed with the Ethics Committee, was to keep in the computer data on those mothers in the selected postal districts that were initially selected as meeting the entry requirements but not selected by the computer to be approached for Groups A to D. It was agreed that this approach identified a free living Group E who would not be biased or sensitised to an eventual dental examination. Toward the end of the study, this fifth group of mothers was traced as still being in the locality and whose children were attending nursery school. They were then approached to agree to the dental examination. This group identified by OPCS at the beginning of the study were never visited and received no DHE. They were examined at 3 years of age for dental caries and oral hygiene in nursery school. At that time, after the dental examination, each mother was given diet and $\mathrm{OHI}$ advice and counselled to ensure that their child visited a dentist regularly.

The programme of DHE visits and clinical examinations is shown in Table 1.

The DHE counseling was based on a script drawn up beforehand and rehearsed so that it followed a standardised format. The dental health messages were based on those of the scientific bases of DHE. ${ }^{13}$ The main message was to substitute bottle with feeder cup; brush child's teeth twice a day with fluoride toothpaste and visit a dentist regularly. At the same time each mother, on every visit, was given the opportunity to ask questions and further advice given accordingly. The two dental health educators were systematically retrained each year.

\section{Questionnaire interview}

A structured questionnaire similar to that used by the National Diet and Nutrition Survey of preschool children ${ }^{14}$ was used to obtain information regarding demographic and socio-economic status of the family, feeding history and dietary habits, dental health and oral hygiene practices.

\section{Clinical examination}

The oral examination of children and their mothers in the study groups was conducted by one of the authors (MBK) in the volunteers' homes with the help of a mouth mirror and a pen light source. No attempt was made to probe the teeth and dental radiographs were not used in any of the examinations. The children in the group E (control) were examined at two nursery schools.

A tooth was considered present when any part if it was visible through the oral mucosa. Initial caries was defined as a demineralised area with loss of translucency and manifested caries as the presence of actual cavitation. The criteria used for caries diagnosis were that of Palmer et al. ${ }^{15}$ To assess intra-examiner reproducibility $10 \%$ of mothers and children were examined twice within a 10-day interval (kappa score $=0.82$ ). The periodontal status was examined by scoring gingivitis, debris (plaque, materia alba) and calculus using the same diagnostic criteria of the Children's Dental Health Survey in the UK. ${ }^{16}$

\section{Statistical analysis}

Differences in age of children and mothers between groups were tested by analysis of variance (ANOVA). Kruskal-Wallis was used to test differences in caries and caries risk factors and the Sign test to examine the changes in mothers' oral health in different phases of the study.

\section{Results}

The children were recruited when they were about 8 months of age and at the baseline examinations the mean age of the children (113 girls and 115 boys) was 11.4 months $(\mathrm{SD}=3.4)$ and of mothers 29.0 years $(\mathrm{SD}=5.3)$. The difference in the mean age of children and mothers between groups was not statistically significant as tested by ANOVA ( $\mathrm{F}=0.49, P=0.69$ and $0.68, P=0.57$ respectively). The majority of children $(96 \%)$ were white Caucasian. The mean number of children in each family was initially 1.8. More than half (115) of mothers had left school at the age of 16 years. The difference in mothers' level of education between groups was not statistically significant $\left(\chi^{2}=5.11, P=0.82\right)$.

Most mothers reported that they had stopped breast feeding when their child reached a mean age of 3.6 months and only 20 (9\%) were still breast feeding at the time of initial interview and examination. However, most of the children $(80 \%)$ were bottle-fed and $40 \%$ of mothers reported that their children fell asleep with bottle/breast nipple in their mouth.

Most $(n=190)$ offered their children sweets, chocolate or sweet biscuits, starting at a mean age 7.14 months $(\mathrm{SD}=2.65)$. Seventyseven infants never used a dummy, 133 still did at baseline (15 sweetened). The most commonly used drink was milk and 146 $(46 \%)$ were given drinks on-demand.

In the second phase of the study (at 2 years of age) two children in group D (those visited yearly) had two initial caries lesions each (demineralisation) on the labial surfaces of their maxillary incisors. One of them was a girl who was breast-fed on-demand and came from a single-parent family. The mothers of these children were advised to visit their dentist for professional fluoride application. In the third phase (at 3 years of age) two children in the study groups had caries, both in diet group A (mean $\mathrm{dmfs}=0.29, \mathrm{SD}=1.64)$ and all remaining children revealed a naturally healthy dentition. In contrast, 18 children (33\%) in group E (control) showed one or more carious lesions (Table 2). The mean dmfs in this group was $1.75(\mathrm{SD}=5.09)$. Twenty-two out of $61(36 \%)$ affected teeth were maxillary incisors, four (7\%) maxillary first molars, 11 (18\%) mandibular first molars, six (10\%) maxillary second molars and 18 (29\%) mandibular second molars.

Only three children (3\%) in the study groups had gingivitis (all in diet group A) and nine (5\%) had poor oral hygiene (three in group $A$ and six in group D). In contrast, nine (16\%) children in group E had gingivitis and $22(40 \%)$ had poor oral hygiene. Thirteen children who had poor oral hygiene in this group also had caries (Table 3). Poor oral hygiene in these children was significantly related to caries $(P<0.001)$.

Eight mothers out of $21(38 \%)$ who returned the questionnaire in group E (control), reported that their children never or rarely

\begin{tabular}{|c|c|c|c|c|c|c|}
\hline \multirow[b]{2}{*}{ Year } & \multirow[b]{2}{*}{ Procedure } & \multicolumn{5}{|c|}{ Cohort groups* } \\
\hline & & A & B & C & D & $\mathrm{E}$ \\
\hline \multirow[t]{4}{*}{1} & Number & 60 & 59 & 60 & 49 & - \\
\hline & Examination I & + & + & + & + & - \\
\hline & Questionnaire & + & + & + & + & - \\
\hline & in months & 3 & 3 & 3 & 12 & - \\
\hline \multirow[t]{4}{*}{2} & Number & 49 & 51 & 56 & 41 & - \\
\hline & Examination II & + & + & + & + & - \\
\hline & $\begin{array}{l}\text { Questionnaire } \\
\text { DHF frequency }\end{array}$ & + & + & + & + & - \\
\hline & $\begin{array}{l}\text { DHE, trequency } \\
\text { in months }\end{array}$ & 3 & 3 & 3 & 12 & - \\
\hline \multirow[t]{4}{*}{3} & Number & 45 & 47 & 51 & 36 & 55 \\
\hline & Examination III & + & + & + & + & + \\
\hline & Questionnaire & + & + & + & + & + \\
\hline & $\begin{array}{l}\text { in months } \\
\text { in frequency }\end{array}$ & 6 & 6 & 6 & 12 & - \\
\hline
\end{tabular}

* $\mathrm{A}=$ diet, $\mathrm{B}=$ oral hygiene, $\mathrm{C}=\operatorname{diet}+\mathrm{OH}, \mathrm{D}=$ yearly $\mathrm{DHE}, \mathrm{E}=$ control tDental health education 
Table 2 Caries prevalence data for children followed for 3 years with dental health education given by home visits

\begin{tabular}{|c|c|c|c|c|c|c|c|}
\hline Group & $\stackrel{n}{S / F}$ & $\begin{array}{l}\text { With caries } \\
n(\%)^{*}\end{array}$ & ds & $\begin{array}{c}\text { Mean caries scores } \\
\text { ms }\end{array}$ & fs & dmfs (SD) & $P$ value \\
\hline $\begin{array}{l}\text { A (diet) } \\
\mathrm{B}(\mathrm{OH}) \\
\mathrm{C} \text { (diet + OH) } \\
\mathrm{D} \text { (yearly DHE) } \\
\mathrm{E} \text { (control) }\end{array}$ & $\begin{array}{l}60 / 45 \\
59 / 47 \\
60 / 51 \\
49 / 36 \\
-/ 55\end{array}$ & $\begin{array}{c}2(4) \\
0 \\
0 \\
0 \\
18(33)\end{array}$ & $\begin{array}{c}0.29 \\
0 \\
0 \\
0 \\
0.78\end{array}$ & $\begin{array}{c}0 \\
0 \\
0 \\
0 \\
0.46\end{array}$ & $\begin{array}{c}0 \\
0 \\
0 \\
0 \\
0.51\end{array}$ & $\begin{array}{c}0.29(1.64) \\
0 \\
0 \\
1.75(5.09)\end{array}$ & $<0.001^{\dagger}$ \\
\hline
\end{tabular}

*Percentages given in parenthesis are rounded and included to assess comparison

${ }^{\dagger}$ As tested by Kruskal-Wallis test

$\mathrm{S}=$ start, $\mathrm{F}=$ finish, $\mathrm{SD}=$ standard deviation of the mean

Table 3 Relationship between caries and oral hygiene in control group $E$ of children, who had received no dental health education

\begin{tabular}{|c|c|c|c|}
\hline Variable & $\begin{array}{c}\text { Caries-free } \\
\text { n (\%) }\end{array}$ & $\begin{array}{c}\text { With caries } \\
n(\%)\end{array}$ & $P$ value \\
\hline $\begin{array}{l}\text { Oral hygiene: } \\
\text { Optimal/good } \\
\text { Poor }\end{array}$ & $\begin{array}{r}28(76) \\
9(24)\end{array}$ & $\begin{array}{r}5(28) \\
13(72)\end{array}$ & 0.001 * \\
\hline
\end{tabular}

* Fisher Exact test

visited a dentist. A comparison of the children's pattern of dental visits, between groups, is presented in Table 4. More than half $(52 \%)$ of the children in the control group were given drinks on demand compared with only five (11\%) in group A, eight (17\%) in group B, five (10\%) in group C and $11(31 \%)$ in group D.

A greater number of children (33\%) in group E (control) were given sweets, chocolate or chocolate biscuits more than once a day compared with those in the study groups (Table 4). Moreover, more children in the study groups were given sweets and/or chocolate either after meals only or at weekends (sweety day) $34(75 \%)$ in group A, 33(70\%) in group B, 32(63\%) in group C, $21(62 \%)$ in group D and only $7(33 \%)$ in group $\mathrm{E}$.

There were more children $(33 \%)$ in the control group who either never or rarely brushed their teeth by 3 years of age. In contrast, the majority of children in the study groups brushed twice a day (Table 4).
There was a statistically significant difference between study and control groups (Table 4 ) in all of the caries risk related factors studied. These were the frequency of dental visits $(P<0.01)$, frequency of drinking, toothbrushing and sweet consumption $(P<0.001)$.

Finally, it was most interesting that the mothers of the children in the study groups also showed a significant improvement in their own oral health and in their frequency of toothbrushing and dental visits. There were more mothers $(85 \%)$ who reported brushing their teeth more than once a day compared with $48 \%$ in the control group. Eight mothers $(38 \%)$ in the control group rarely or never brushed their teeth compared with only three (2\%) among the study mothers. This difference in the frequency of mothers' toothbrushing was statistically significant as tested by the Kruskal-Wallis test $(\mathrm{H}=40.83, P<0.001)$. One third of mothers in the control group never or rarely (ie only in case of pain) visited the dentist compared with $16(9 \%)$ in the study groups. This difference in the number of mothers who never or rarely and those who regularly visited the dentist between groups was statistically significant $(P<0.05)$. In comparing the gingivitis, debris and calculus scores of the mothers of the children in the study groups (Table 5), in the first and second phases and also first and third phases of the study, recorded a statistically significant difference $(P<0.001)$, with an improvement of all scores for gingivitis and plaque.

The mean DMFT of mothers in first, second and third oral examinations was $9.7(\mathrm{SD}=5.3), 10.2(\mathrm{SD}=5.3)$ and $10.4(\mathrm{SD}=$ $5.1)$, respectively. The differences in the mean DMFT were not statistically significant.

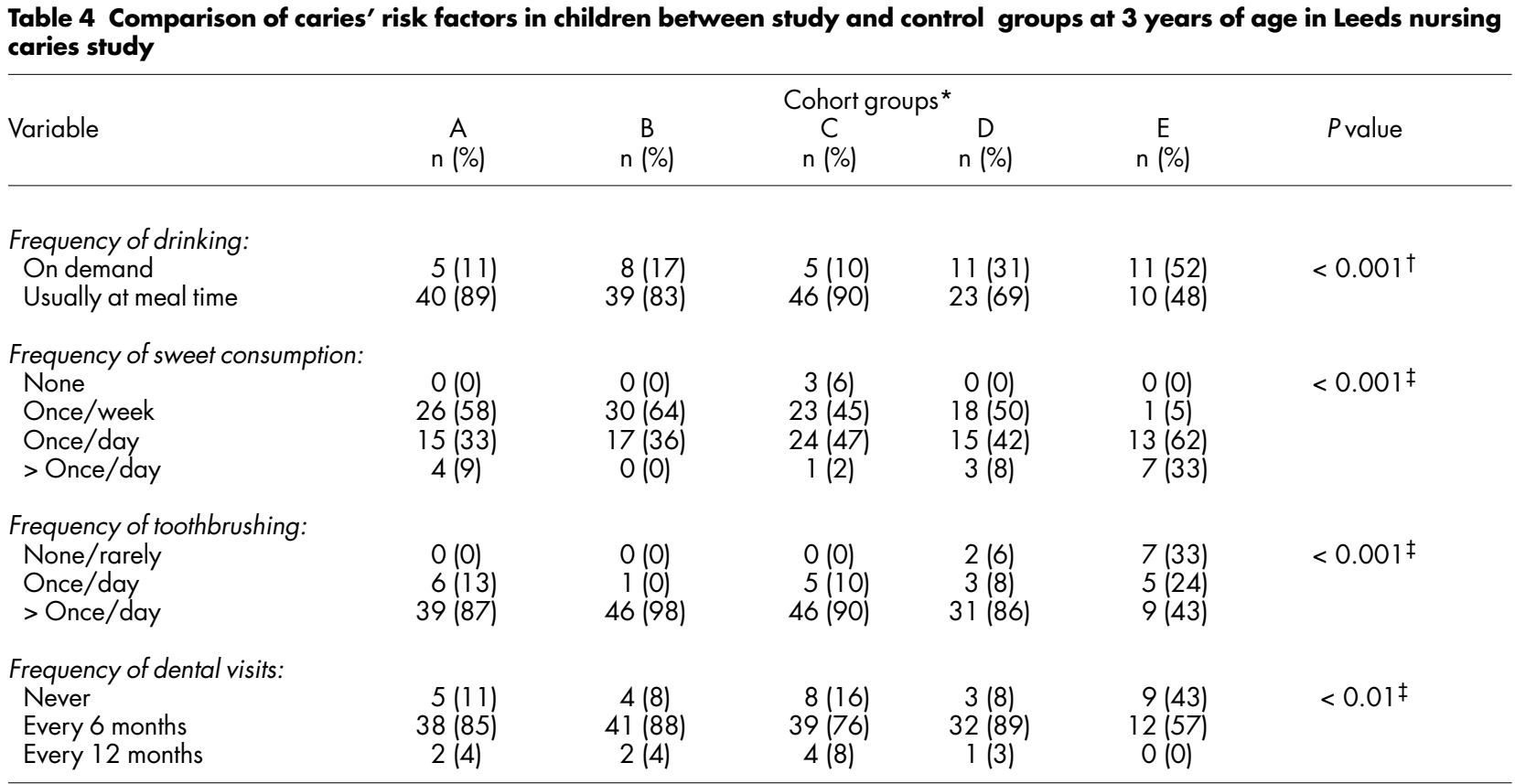

* $\mathrm{A}=$ diet, $\mathrm{B}=$ oral hygiene, $\mathrm{C}=\operatorname{diet}+\mathrm{OH}, \mathrm{D}=$ yearly $\mathrm{DHE}, \mathrm{E}=$ control

${ }^{\mathrm{A}} \mathrm{Chi}{ }^{2},{ }^{\prime}$ Kruskal-Wallis 


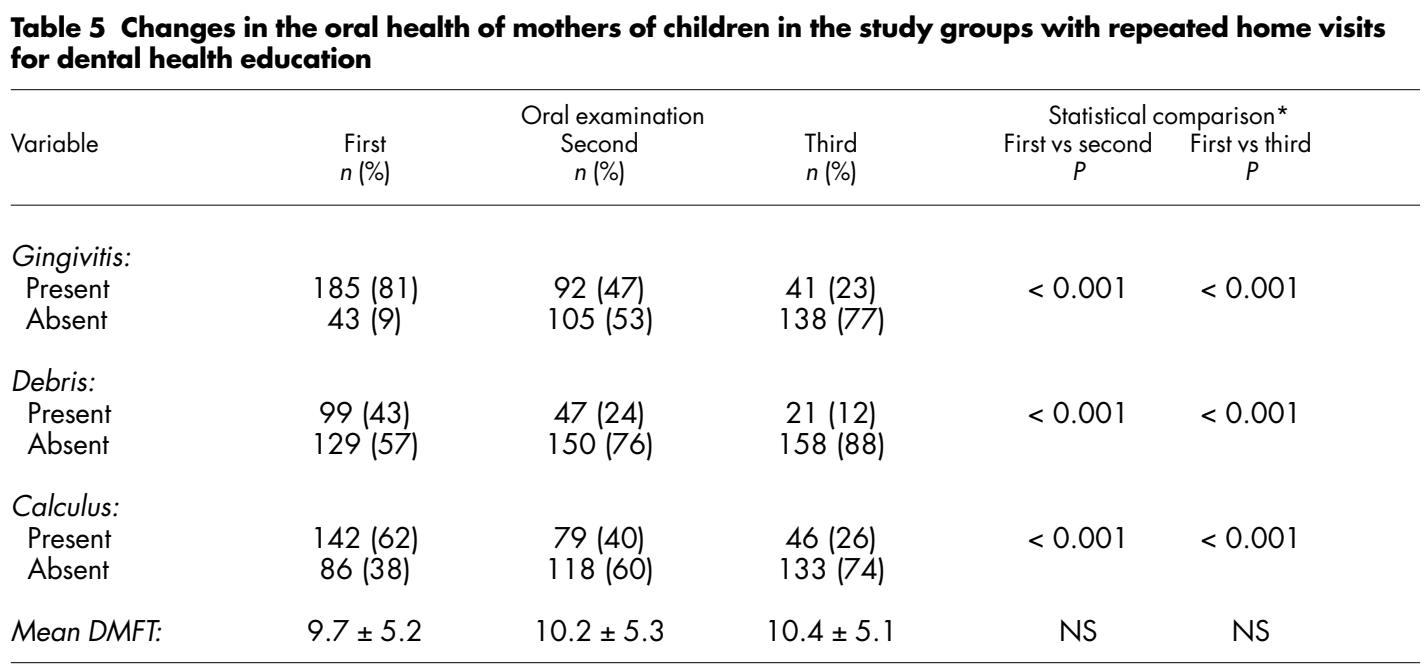

* As tested by the Sign test. NS $=$ not significant

\section{Discussion}

There are only a few prospective intervention studies reported in the literature with a relatively brief contact with mothers which in most cases occured too late. ${ }^{11} \mathrm{DHE}$ as a preventive strategy also is rarely studied and evaluated in a randomised way. ${ }^{12}$

The main finding from this study was that repeated visits to provide DHE to mothers of young infants in their own homes was very successful in preventing the occurrence of nursing caries. It was significant that even by the third annual dental examination only two children, in group A (DHE focussed on diet) had developed caries and the lesions were confined to the maxillary central incisors. In the groups where a major component of the DHE was oral hygiene instruction, including the use of low fluoride toothpaste, the children did not develop any lesions at all.

The findings are further emphasised when the comparison was made with the control group children (E). This group were examined only when they had reached the age of three years. These children were originally in the OPCS (Office of Population Census and Survey) statistical list of children born with the required postal districts but not selected by the computer for possible participation in the main study groups. They resided in the same geographic areas as the selected children and had the same socio-economic background. These children received no DHE at all, and showed a poor record of contact with dental professionals and were found to have a significantly higher level of dental caries (33\%). A higher level of dental caries in at-risk preschool children has also been reported by previous national and international studies. ${ }^{17-21}$

A comparison of the active groups A, B and C with D would seem to indicate there was no difference between visiting every 3 months with every 12 months. This may have cost implications if the successful approach, tested here, were to be implemented as a dental public health strategy. To have a DH Educator visit only twice a year would obviously be more cost effective. The two educators in this study were a dental hygienist and an outreach paediatric nursing sister. One therefore had a dental background and one a paediatric. Both were given the same DHE training and visited children in all groups equally. There were no differences between the dental caries or oral hygiene results for the two visitors. The implication here is that it may well be that midwives and health visitors could be just as effective as dental personnel. However, they should be suitably trained in DHE as many previous reports have shown that they are often poorly informed about dental health, as the majority of training courses do not include dental health in their curricula. ${ }^{22-24}$ The home visit is, in our opinion, important to give DHE in a family environment.
Another finding of note was the improvement in the mothers' oral health. While the study did probably not run long enough to show a significant change in the incidence of dental caries, there was an effect on oral hygiene practice. This was an unpredicted but valuable benefit. Further research is needed here into the effects of repeated or regular DHE on family dental health.

\section{Conclusion}

Regular home visits to mothers with infants, commencing at or soon after the time of the eruption of the first deciduous teeth, was shown to be effective in preventing the occurrence of caries, improving oral hygiene and dental attendance. There was no difference in effect between a visit every 3 months or every 12 months between the ages of 1 and 3 years. An added benefit was that the mothers of the children also significantly improved their oral hygiene in terms of debris, gingivitis and calculus.

The authors wish to express their great appreciation to the mothers of the children in this study for their continued interest and cooperation throughout the study. The authors also appreciate the help of Mr. G. Faripo in the statistical analysis of the results. This research was partially funded by a grant from The Sugar Bureau (London).

1 O'Sullivan E A, Williams S A, Cape J E, Wakefield R C, Curzon M E J. Prevalence and site characteristics of dental caries in primary molar teeth from prehistoric times to the 18th century in England. Caries Res 1993; 27 : 147-153.

2 Curzon M E J, Pollard M A. Nursing caries: the extent and nature of the problem. In Curzon M E, Diehl J M, Ghraft R, Lentze M J. International workshop in carbohydrate in infant nutrition and dental health (pp 19-30). Munchen: Urban and Vogel, 1994.

3 Blinkhorn A S. The caries experience and dietary habits of Edinburgh nursery school children. Br Dent J 1982; 152: 227-230.

4 Holt R D, Joels D, Bulman J, Maddick I H. A third study of caries in preschool aged children in Camden. Br Dent J 1988; 165: 87-91.

5 Ripa L W. Nursing caries: a comprehensive review. Pediatr Dent 1988; 10: 268-271.

6 Berkowitz R J, Turner J, Green P. Primary oral infection of infants with streptococcus mutans. Arch Oral Biol 1980; 25: 221-224.

7 Weinstein P, Oberg D, Domoto P K, Jeffcott E, Leroux B. A prospective study of the feeding and brushing practices of WIC mothers: Six and twelve-months data and ethnicity and familial variables. J Dent Child 1996; 63: 113-117.

8 Holt R D, Winter, G B, Fox B, Askew R, Lo G L. Dental health education through home visits to mothers with young children. Community Dent Oral Epidemiol 1983; 11: 98-101.

9 Lee C, Rezaiamiri N, Jeffcott E, Oberg D, Domoto P, Weinstein P. Teaching parents at WIC clinics to examine their high caries risk babies. J Dent Child 1994; 61: 347-349.

10 Kohler B, Bratthall D, Krasse B. Preventive measures in mothers influence 


\section{dental health education}

the establishment of bacterium streptococcus mutans in their infants. Arch Oral Biol 1983; 28: 225-231.

11 Weinstein P. Research recommendations: pleas for enhanced research efforts to impact the epidemic of dental disease in infants. J Publ Heal Dent 1994; 56: 55-60.

12 Kay E J, Locker D. Is dental health education effective? A systematic review of current evidence. Community Dent Oral Epidemiol. 1996; 24: 231-235.

13 Levine R S. The scientific bases of dental health education. A policy document. London: Health Education Council, 1985.

14 Hinds K, Gregory T. National diet and nutrition survey: children aged 1.5 to 4.5 years. Volume 2. Report of the dental survey. London: HMSO, 1995.

15 Palmer J D, Anderson R J, Downer M C. Guidelines for prevalence studies of dental caries. Community Dent Oral Epidemiol 1984; 1: 55-66.

16 Todd J E, Dodd T. Children's dental health in the UK 1983. London: OPCS, Social Survey Division, 1985.

17 Winter G B, Rule D C, Mailer G P, James P M, Gordon P H. The prevalence of dental caries in pre-school children aged 1 to 4 years. Br Dent J 1971; 130: 271-277.
18 Sutcliffe P. Caries experience and oral cleanliness of 3- and 4-year-old children from deprived and non-deprived areas in Edinburgh, Scotand. Community Dent Oral Epidemiol 1977; 5: 213-219.

19 Prendergast M L, Williams S A, Curzon M E J. An assessment of dental caries prevalence among Gujurati, Pakistani and White Caucasian fiveyear-old children resident in Dewsbury, West Yorkshire. Community Dent Health 1989; 6: 223-232.

20 O'Brien M. Children's dental health in the United Kingdom 1993. London: HMSO, Social Survey Division, 1994.

21 Wendt L-K, Hallonsten A, Koch G. Oral health in preschool children living in Sweden. Part II- A longitudinal study. Findings at three years of age. Swed Dent J 1992; 16: 41-49.

22 William S A. Dental Health Teaching and Health visitors. Health EducJ 1980; 39: 119-122.

23 Quinn G, Freeman R. Health visitors as dental health educators: their knowledge, attitude and behaviours. Health Educ J 1991; 50: 191-194.

24 Hunter M I, Hunter B, Chadwick B. The current status of dental health education in the training of midwives and health visitors. Community Dent Health 1996; 13: 44-46. 